\title{
COMPARISON OF RIPASA AND ALVARADO SCORING SYSTEM IN ACUTE APPENDICITIS- A DESCRIPTIVE STUDY
}

\author{
Thameen Ansara $S^{1}$, Vishnu Kumar $S^{2}$ \\ ${ }_{1}^{1}$ Assistant Professor, Department of General Surgery, Chennai Medical College Hospital and Research Centre, Irungalur, Trichy, \\ Tamilnadu. \\ ${ }^{2}$ Assistant Professor, Department of General Surgery, Chennai Medical College Hospital and Research Centre, Irungalur, Trichy, \\ Tamilnadu.
}

\begin{abstract}
BACKGROUND
ABSTRACT

Acute appendicitis is the most common cause of an acute abdomen requiring surgery with a lifetime risk of about 7\%. Even with recent advances in imaging modalities, considerable morbidity continues to be associated with appendicitis. Diagnostic delay leads to perforation and other complications increasing the morbidity. Scoring systems were introduced to reduce the rate of negative appendicectomy. Alvarado designed a 10-point clinical scoring system, where a score of $\geq 7$ warrants appendicectomy. Recently, RIPASA scoring system was implemented to overcome the problems with Alvarado scoring system based on 14 fixed clinical parameters, where a score of $\geq 7.5$ warrants a surgical intervention.

Our study compares the Alvarado and RIPASA scoring system in diagnosing acute appendicitis and correlate with histopathological findings.
\end{abstract}

\section{MATERIALS AND METHODS}

The descriptive study with patients who presented to our Emergency/ General Surgery Department from January 2016 to October 2016 with right iliac fossa pain and who were suspected of acute appendicitis were considered for the study. Of them, hundred patients who satisfied our inclusion criteria were enrolled in our study. A detailed history, clinical examination and laboratory investigations were done for all. Scores were obtained for all the patients using both the Alvarado and RIPASA scoring systems. All the patients underwent appendicectomy. Histopathological diagnosis was considered as gold standard. Sensitivity, specificity, positive predictive value and negative predictive value for both these scorings were calculated and analysed comparatively with a Chi-square test.

\section{RESULTS}

Out of 100 patients, 57 were male and 43 were female. Both the scoring system were obtained and correlated with histopathological findings. As per Alvarado scoring, 58 patients had a score of $\geq 7$ and 42 patients had a score of $<7$. On applying the RIPASA scoring system, 73 patients had a score of $\geq 7.5$ and 27 patients had a score of $<7.5$. The specimens of all the hundred patients were examined, of which 74 showed features of acute appendicitis histopathologically. The sensitivity of Alvarado and RIPASA was $68.92 \%$ and $91.89 \%$ respectively. The diagnostic accuracy was $70 \%$ by Alvarado compared to $89 \%$ by RIPASA. The negative appendectomy rate by Alvarado scoring was $12.06 \%$ and $6.85 \%$ by RIPASA.

\section{CONCLUSION}

Our study concluded that RIPASA score is a simple and rapid system with higher sensitivity compared to the Alvarado score. The NPV (Negative Predictive Value) and diagnostic accuracy was also higher with RIPASA scoring system in our study population. Hence, RIPASA scoring system is better than Alvarado scoring system in establishing the diagnosis of acute appendicitis.

\section{KEYWORDS}

Acute Appendicitis - Alvarado Scoring System - RIPASA Scoring System.

HOW TO CITE THIS ARTICLE: Ansari TS, Kumar VS. Comparison of RIPASA and Alvarado scoring system in acute appendicitis- a descriptive study. J. Evolution Med. Dent. Sci. 2018;7(15):1872-1876, DOI: 10.14260/jemds/2018/422

\section{BACKGROUND}

Appendix is a diverticulum arising from the caecum approximately $2 \mathrm{~cm}$ below the ileocaecal junction. The length varies from 2 to $20 \mathrm{~cm}$ with an average length of $9 \mathrm{~cm}$. The most common position is retrocaecal (65\%).[1] Acute appendicitis is the most common cause of an acute abdomen

'Financial or Other Competing Interest': None.

Submission 01-03-2018, Peer Review 25-03-2018,

Acceptance 31-03-2018, Published 09-04-2018.

Corresponding Author:

Dr. Vishnu Kumar $S$,

Assistant Professor, Department of General Surgery,

Chennai Medical College Hospital and Research Centre,

Irungalur, Trichy, Tamilnadu.

E-mail: vichu.doc08@gmail.com

DOI: $10.14260 /$ jemds $/ 2018 / 422$

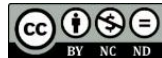

requiring surgery with a lifetime risk of about 7\%.[2] It is also the most common indication in emergency abdominal surgery comprising about $10 \% .{ }^{[3]}$ Appendicitis is most common in the second decade of life and is slightly more common in males than in females.[4] The incidence is 1.4 times increased in men than in women. ${ }^{[5]}$

The diagnosis of acute appendicitis depends mostly on the presenting symptoms and clinical examination findings. The confirmative diagnosis of appendicitis is done only by histopathological examination, which is impossible before surgery. So, it is very important to diagnose acute appendicitis at the time of presentation to reduce the postoperative morbidity and mortality.

A delay in the diagnosis of acute appendicitis may lead to complications like appendicular perforation, which increases the morbidity and mortality especially in infants and 
elderly. ${ }^{[4]}$ Although, the overall mortality is less than $1 \%$, the incidence ranges between $5 \%$ and $15 \%$ in elderly and infants respectively.[6]

Symptoms of appendicitis overlap with a number of other conditions making diagnosis a challenge, particularly in children.[7] Clinical conditions that mimic appendicitis may delay the diagnosis. The incidence of misdiagnosis rates were higher in females than males.[8] In females pelvic inflammatory disease, torsion ovarian cyst and sometimes ectopic pregnancy may mimic appendicitis.

So a definite systematic evaluation for diagnosing a patient with acute appendicitis is required. Alvarado designed a 10-point clinical scoring system with the pneumonic MANTRELS for the diagnosis of acute appendicitis in 1986 [Table 1]. It was based on symptoms, clinical signs and laboratory values in patients presenting with the suspicion of acute appendicitis.[9] Although used for more than two decades, this scoring system is not completely reliable.

A recent clinical policy documented from the American College of Emergency Physicians review states that the Alvarado score can be used to 'rule out' appendicitis at a score below five points (sensitivity $94 \%$ to $99 \%$ ), but not as a 'rule in' for appendicitis. ${ }^{[10]}$

In 2010, RIPASA scoring system was introduced [Table 2]. The Raja Isteri Pengiran Anak Saleha Appendicitis [RIPASA] score is a simple qualitative scoring system based on a 14 fixed clinical parameters (two demographics, five clinical symptoms, five clinical signs and two clinical investigations) and one additional parameter (foreign national identity).[3] RIPASA score showed a sensitivity and specificity of $88 \%$ and $67 \%$ with a diagnostic accuracy of $81 \%$.[11] The sensitivity and specificity of RIPASA score in diagnosing acute appendicitis was equivalent to that achieved with CT scan of abdomen.[12] Hence, RIPASA scoring system reduced the number of CT scans done for appendicitis.

The RIPASA score is simple and easy to calculate. The 14 clinical parameters can be easily obtained with a detailed clinical history and a good clinical examination. Urine analysis included in the scoring system can also be obtained easily. So the final score can be calculated quickly and a rapid diagnosis of acute appendicitis can be made without the need for other investigations and when a score of $>7.5$ is obtained we can proceed with surgical intervention. The 14 fixed clinical parameters are general to all populations and hence the RIPASA score can be applied in any country.[3]

The aim of study was to compare RIPASA and Alvarado scoring in diagnosing acute appendicitis and also to correlate with intraoperative and histopathological findings.

\section{MATERIALS AND METHODS}

The descriptive study with patients who presented to our Emergency/ General Surgery Department from January 2016 to October 2016 with right iliac fossa pain and who were suspected of acute appendicitis were considered for the study. Patients of all age groups admitted with complaints of right iliac fossa pain with clinical suspicion of acute appendicitis were included. Patients with pain in the right iliac fossa for more than 5 days who were suspected to have appendicular mass, patients with features of generalised peritonitis, patients with previous history of renal or ureteric stones and patients with pelvic inflammatory disease were excluded.

Hundred patients with clinical suspicion of acute appendicitis were enrolled into the study. Once the patient satisfies the inclusion criteria, a detailed history, clinical examination and laboratory investigations were done, which included routine haematological investigations, urine routine, $\mathrm{x}$-ray KUB and USG abdomen and pelvis was done in for all.

Proforma for the two scoring systems were filled in for each patient. One proforma had general information about the patient with the eight variables of the Alvarado scoring system and the other proforma had similar patient details with the fourteen variables of RIPASA scoring system. The Alvarado score and RIPASA score were noted independently. After obtaining a proper informed and written consent for surgery, all the patients underwent appendicectomy.

The diagnosis of acute appendicitis was confirmed by intraoperative findings and also by histopathological assessment of the appendicectomy specimen. The presence of polymorphonuclear leucocytes throughout the thickness of the appendicular wall was the ultimate criteria for the final diagnosis of acute appendicitis histopathologically. Sensitivity, specificity, positive predictive value and negative predictive value for both these scorings were calculated and analysed comparatively with a Chi-square test (SPSS Software v 17.0).

\section{RESULTS}

Of the hundred patients included in the study, the age of the patients varied from minimum of 13 years to a maximum of 71 years [Table 3]. More number of patients were in the age group of 20 to 40 years of age with a mean age of 32.16 . Among the 100 patients, 57 were male and 43 were female with a male-to-female ratio of 1.33: 1 .

Based on symptoms, all the 100 patients had right iliac fossa pain. Anorexia was the next predominant symptom present in about 81 patients. Fever was present in 52 patients. Nausea and vomiting was present in 63 patients and migratory pain to the right iliac fossa was present in 56 patients only. 40 patients presented to us within 48 hours of onset of symptoms [Table 4].

Regarding signs, right iliac fossa tenderness was present in all the patients with rebound tenderness in 76 patients, guarding in 47 patients and a positive Rovsing's sign only in 24 patients. Elevated white blood cell count was observed in 51 patients and a normal urine microscopy was present in 87 patients [Table 5].

As per Alvarado scoring, 58 patients had a score of $\geq 7$ and 42 patients had a score of $<7$. On applying the RIPASA scoring system 73 patients had a score of $\geq 7.5$ and 27 patients had a score of $<7.5$. The intra-operative details were noted which showed an inflamed appendix in 89 patients, perforated appendix and gangrenous appendix in 8 and 3 patients respectively. The mean hospital stay was $4.3 \pm 2$ days.

The specimens of all the hundred patients were examined, of which 74 showed features of acute appendicitis and 26 were found to be normal histopathologically.

According to Alvarado scoring system, 58 patients were diagnosed to have acute appendicitis. Of these 51 patients had histological evidence of acute appendicitis. Seven patients who had an Alvarado score of more than 7 had no 
evidence of appendicitis histologically. Of the 42 patients with Alvarado score less than 7 , twenty three patients who had features of acute appendicitis in the specimen were missed by this scoring system [Table 6]. The sensitivity of this scoring system in the study was $68.92 \%(57.1 \%-79.17 \%)$, specificity was $73.08 \%(52.21 \%-88.43 \%)$. The positive predictive value was $87.93 \%(79.16 \%-93.32 \%)$ and the negative predictive value was $45.25 \%$ (35.37\% - 55.5\%). The diagnostic accuracy was $70 \%(60.02 \%-78.76 \%)$. The negative appendicectomy rate was $12.06 \%$.

According to RIPASA scoring system, 73 patients were diagnosed to have acute appendicitis. Of these 68 patients had histological evidence of acute appendicitis [Table 7]. Five patients with a RIPASA score of more than or equal to 7.5 had a histologically normal appendix. Of the 27 patients with RIPASA score less than 7.5, only six patients who had histological evidence of acute appendicitis in the specimen were missed by this scoring system. The sensitivity of this scoring system in the study was $91.89 \%(83.18 \%-96.97 \%)$, specificity was $80.77 \%(60.65 \%-93.45 \%)$. The positive predictive value was $93.15 \%(86.05 \%-96.77 \%)$ and the negative predictive value was $77.78 \%(61.38 \%-88.52 \%)$ The diagnostic accuracy was $89 \%(81.17 \%$ - 94.38\%). The negative appendicectomy rate was $6.85 \%$.

On analysing the Cross Table 8 by Fisher's exact test, there is a definitive agreement that the two scoring systems are correlating positively with each other with respect to the diagnosis of the disease with p-value of 0.0031 .

\begin{tabular}{|c|c|}
\hline Symptoms & Score \\
\hline M= Migratory RIF pain & 1 \\
\hline $\mathrm{A}=$ Anorexia & 1 \\
\hline $\mathrm{N}=$ Nausea, vomiting & 1 \\
\hline $\mathrm{T}=\mathrm{RIF}$ tenderness & 2 \\
\hline $\mathrm{R}=$ Rebound tenderness & 1 \\
\hline $\mathrm{E}=$ Elevated temperature & 1 \\
\hline $\mathrm{L}=$ Leucocytosis & 2 \\
\hline$S=$ Shift to left (neutrophilia) & 1 \\
\hline Total & 10 \\
\hline \multicolumn{2}{|c|}{ Table 1. Alvarado Scoring System } \\
\hline
\end{tabular}

\begin{tabular}{|c|c|c|}
\hline \multicolumn{2}{|c|}{ Parameter } & Score \\
\hline \multirow{2}{*}{ Gender } & Male & 1.0 \\
\cline { 2 - 3 } & Female & 0.5 \\
\hline \multirow{2}{*}{ Age } & $<39.9$ years & 1.0 \\
\cline { 2 - 3 } & $>40.0$ years & 0.5 \\
\hline \multicolumn{2}{|c|}{ RIF pain } & 0.5 \\
\hline \multicolumn{2}{|c|}{ Migratory RIF pain } & 0.5 \\
\hline \multicolumn{2}{|c|}{ Anorexia } & 1.0 \\
\hline \multicolumn{2}{|c|}{ Nausea and vomiting } & 1.0 \\
\hline Duration of & $<48$ hours & 1.0 \\
\cline { 2 - 3 } Symptoms & $<48$ hours & 0.5 \\
\hline \multicolumn{2}{|c|}{ RIF Tenderness } & 1.0 \\
\hline \multicolumn{2}{|c|}{ Guarding } & 2.0 \\
\hline \multicolumn{2}{|c|}{ Rebound Tenderness } & 1.0 \\
\hline \multicolumn{2}{|c|}{ Rovsing's Sign } & 2.0 \\
\hline \multicolumn{2}{|c|}{ Fever } & 1.0 \\
\hline \multicolumn{2}{|c|}{ Raised WBC Count } & 1.0 \\
\hline \multicolumn{2}{|c|}{ Negative Urine Analysis } & 1.0 \\
\hline \multicolumn{2}{|c|}{ Foreign NRIC } & 1.0 \\
\hline \multicolumn{2}{|c|}{ Table 2. RIPASA Scoring System } \\
\hline \multicolumn{2}{|c|}{}
\end{tabular}

\begin{tabular}{|c|c|}
\hline AGE (Years) & Total \\
\hline$<20$ & 14 \\
\hline $21-40$ & 63 \\
\hline $41-60$ & 18 \\
\hline$>60$ & 5 \\
\hline \multicolumn{2}{|c|}{ Table 3. Age Distribution } \\
\hline
\end{tabular}

\begin{tabular}{|c|c|c|}
\hline Symptoms & Frequency & Percentage \\
\hline Right iliac fossa pain & 100 & 100 \\
\hline Anorexia & 81 & 81 \\
\hline Fever & 52 & 52 \\
\hline Nausea and vomiting & 63 & 63 \\
\hline Migratory pain & 56 & 56 \\
\hline Duration < 48 hours & 40 & 40 \\
\hline \multicolumn{2}{|c|}{ Table 4. Symptom Distribution } \\
\hline
\end{tabular}

\begin{tabular}{|c|c|c|}
\hline Signs & Frequency & Percentage \\
\hline RIF Tenderness & 100 & 100 \\
\hline Rebound Tenderness & 76 & 76 \\
\hline Guarding & 42 & 42 \\
\hline Rovsing's Sign & 24 & 24 \\
\hline \multicolumn{2}{|c|}{ Table 5. Signs Distribution } \\
\hline
\end{tabular}

\begin{tabular}{|c|c|c|c|}
\hline & $\begin{array}{c}\text { Positive } \\
\text { Histology }\end{array}$ & $\begin{array}{c}\text { Negative } \\
\text { Histology }\end{array}$ & Total \\
\hline Alvarado $>7$ & 51 & 7 & 58 \\
\hline Alvarado $<7$ & 23 & 19 & 42 \\
\hline Total & $\mathbf{7 4}$ & $\mathbf{2 6}$ & $\mathbf{1 0 0}$ \\
\hline \multicolumn{3}{|c|}{ Table 6. Alvarado Score and Histopathology } \\
\hline
\end{tabular}

\begin{tabular}{|c|c|c|c|}
\hline & $\begin{array}{c}\text { Positive } \\
\text { Histology }\end{array}$ & $\begin{array}{c}\text { Negative } \\
\text { Histology }\end{array}$ & Total \\
\hline RIPASA $>7.5$ & 68 & 5 & 73 \\
\hline RIPASA $<7.5$ & 6 & 21 & 27 \\
\hline Total & 74 & 26 & $\mathbf{1 0 0}$ \\
\hline \multicolumn{2}{|c}{ Table 7. RIPASA Score and Histopathology } \\
\hline
\end{tabular}

\begin{tabular}{|c|c|c|c|}
\hline & RIPASA $>$ 7.5 & RIPASA $<\mathbf{7 . 5}$ & Total \\
\hline Alvarado $>7$ & 49 & 9 & 58 \\
\hline Alvarado $<7$ & 24 & 18 & 42 \\
\hline Total & $\mathbf{7 3}$ & $\mathbf{2 7}$ & $\mathbf{1 0 0}$ \\
\hline Table 8. Qualitative Analysis of both Scoring Systems \\
\hline
\end{tabular}

(P value- 0.0031)

\begin{tabular}{|c|c|c|}
\hline Statistical Analysis & Alvarado & RIPASA \\
\hline Sensitivity & $68.92 \%$ & $91.89 \%$ \\
\hline Specificity & $73.08 \%$ & $80.77 \%$ \\
\hline Positive predictive value & $87.93 \%$ & $93.15 \%$ \\
\hline Negative predictive value & $45.25 \%$ & $77.78 \%$ \\
\hline Diagnostic accuracy & $70.00 \%$ & $89.00 \%$ \\
\hline Negative appendicectomy rate & $12.06 \%$ & $6.85 \%$ \\
\hline \multicolumn{2}{|c|}{ Table 9. Comparison between Alvarado and RIPASA } \\
Scoring with Respect to Different Variables \\
\hline
\end{tabular}

\section{DISCUSSION}

Acute appendicitis is the most common surgical emergency encountered in call duties accounting for $10 \%$ of all emergency abdominal surgeries. ${ }^{[3]}$ It is also the most common emergency surgical condition in the age group of less than 30 years in the world.[13] The diagnostic accuracy of clinical assessment of acute appendicitis varies from 50\% - 80\%.[14] In children, elderly and in women of reproductive age group 
the clinical diagnosis is especially difficult. Hence, we have to rule out the conditions which mimic appendicitis. [7,8]

Radiological methods such as ultrasonography and computed tomography are methods that have been investigated. CECT scan of abdomen is an investigation, which has a high sensitivity and specificity in diagnosing acute appendicitis and its complications. But this investigation cannot be affordable and feasible for every patient with right iliac fossa pain in countries with limited resources.[15,16]

Appendicitis is still a diagnostic challenge for even experienced surgeons. Many investigations have been done in the past trying to reduce the removal of a normal appendix without increasing the rate of complications of appendicitis like perforation and abscess formation. Many diagnostic scores advocated earlier are complex and difficult to implement in a clinical scenario.

The Alvarado score is a simple scoring system first described in 1986. The Alvarado criterion for the diagnosis of acute appendicitis was later modified to accommodate additional parameters along with original Alvarado scoring system.[9] Since then, the modified Alvarado scoring system has been the most widely used scoring system for acute appendicitis. Studies done recently showed poor results in diagnostic accuracy of Alvarado scoring system in Asian populations when compared to western literature.

This led to the development of a newer scoring system in 2010 by Chong et al called RIPASA scoring that included 14 fixed parameters.[11] Data showed a significantly increased accuracy in diagnosing acute appendicitis and was claimed to have better outcomes in the Asian populations. Their study compared the Alvarado scoring with the newer RIPASA scoring in local population group with respect to correlation between the scores and histopathological findings.[11,17]

Our study group had 100 cases of acute appendicitis based on clinical suspicion alone with more number of patients in the age group of 20 to 40 years. There were 57 males and 43 females in the study population. All patients underwent surgery and the intra-operative parameters were noted. Histopathological examination was considered the gold standard for confirmation of the diagnosis. According to histopathological examination, 74 patients were in the appendicitis group and 26 were in the no appendicitis group.

On applying Alvarado scoring system in the study group, $58 \%$ of cases had a score of $\geq 7$ and $42 \%$ had a score of $<7$. On comparing with the histopathological analysis in this study, the sensitivity was $68.92 \%$, specificity was $73.08 \%$ with a positive and negative predictive value of $87.93 \%$ and $45.25 \%$ respectively. The diagnostic accuracy was 70\%. The negative appendicectomy rate was $12.06 \%$. Regar MK et al reported a sensitivity and specificity of $67.37 \%$ and $80 \%$ respectively. The positive and negative predictive values of Alvarado score were $98.46 \%$ and $11.43 \%$. Negative appendicectomy rate in that study was $1.54 \% .{ }^{[18]}$ The sensitivity in our study was $68.92 \%$ which was almost comparable with the quoted study, specificity being $7 \%$ lower in our study with the quoted study.

Jawaid et al, Dey S et al, Baidya et al and Chan et al concluded that the sensitivity, specificity, positive predictive value and negative predictive value of Alvarado scoring system ranged from $59 \%$ to $89 \%, 23 \%$ to $70 \%, 77 \%$ to $98 \%$ and $69.8 \%$ to $98 \%$ respectively.[19,20,21] When the RIPASA scoring system was applied, 73 patients had a score of $\geq 7.5$ and 27 had a score of $<7.5$. On histopathological analysis the sensitivity of our study was $91.89 \%$, specificity was $80.77 \%$, positive and negative predictive values were $93.15 \%$ and $77.78 \%$ respectively. Negative appendicectomy rate was $6.85 \%$ and diagnostic accuracy was $89 \%$. Chong et al found a sensitivity and specificity of $88 \%$ and $67 \%$ respectively with a positive and negative predictive value of $93 \%$ and $53 \%$ respectively. A diagnostic accuracy of $81 \%$ was obtained.[11]

Thus, in our study the Alvarado score failed to diagnose $54.7 \%$ of patients $(n=23)$ with acute appendicitis and wrongly classified them in the low-probability group (Alvarado score $<7.0$ ). The RIPASA score was more sensitive and specific compared to the Alvarado scoring system. The difference in diagnostic accuracy was 19\% between the Alvarado score and RIPASA score, indicating that the RIPASA score is a much better diagnostic tool for diagnosing acute appendicitis in our patient population.

At the same time patients who were classified as lowprobability of having acute appendicitis (i.e. true negative group with RIPASA score $<7.5$ and Alvarado score $<7.0$ ), the RIPASA score again outperformed the Alvarado score by correctly diagnosing $77.78 \%$ of patients who did not have acute appendicitis compared with the Alvarado score, which correctly diagnosed in only $45.25 \%$.

The RIPASA score is a simple, good and rapid diagnostic tool in acute appendicitis, especially in the emergency situation as it requires only the patient's demographics (age, gender), a detailed clinical history (RIF pain, migratory pain to RIF, anorexia, nausea and vomiting), clinical examination (fever, RIF tenderness, guarding, rebound tenderness and Rovsing's sign) and two simple investigations (elevated white blood cell count and negative urine analysis).

Thus, a quick decision making can be made on examining the patients with right iliac fossa pain in the emergency setting. A RIPASA score of $>7.5$ needs admission and further surgical intervention, while patients with a RIPASA score $<7.5$ can be put on conservative management and observed.

The RIPASA score has a high sensitivity (91.89\%) and NPV (77.78\%), which can reduce the unwarranted radiological investigations like a CT imaging which is also expensive.[22,23,24]

\section{CONCLUSION}

Our study concluded that RIPASA score is a simple and rapid system with higher sensitivity compared to the Alvarado score. The NPV and diagnostic accuracy was also higher in RIPASA scoring system in our study population. With a detailed history, clinical examination and two simple investigations, all the 14 fixed parameters can be easily obtained in any population. For medical professionals in a rural setup, RIPASA score can help in making a quick decision whether to proceed with surgery or to put on conservative management.

\section{REFERENCES}

[1] Sabiston DC. Sabiston's textbook of surgery. The biological basis of modern surgical practice. $19^{\text {th }}$ edn. Philadelphia, PA: Saunders 2012;2: p. 1279.

[2] Ergul E. Importance of family history and genetics for the prediction of acute appendicitis. Internet J Surg 2007;10:2. 
[3] Chong CF, Thien A, Mackie AJA, et al. Evaluation of the RIPASA Score: a new scoring system for the diagnosis of acute appendicitis. Brunei Int Med J 2010;6(1):1726.

[4] Addiss DG, Shaffer N, Fowler BS, et al. The epidemiology of appendicitis and appendectomy in the United States. Am J Epidemiol 1990;132(5):910-25.

[5] Cuschieri A. The small intestine and vermiform appendix. In: Cuscheri A, Giles GR, Mossa AR. eds. Essential surgical practice. 3rd edn. London: Butterworth Heinman 1995: p. 1325-8.

[6] Mueller BA, Daling JR, Moore DE, et al. Appendectomy and the risk of tubal infertility. N Engl J Med 1986;315(24):1506-8.

[7] Bundy DG, Byerley JS, Liles EA, et al. Does this child have appendicitis? JAMA 2007;298(4):438-51. doi: 10.1001/jama.298.4.438.

[8] Flum DR, Morris A, Koepsell T, et al. Has misdiagnosis of appendicitis decreased over time? A population based analysis. JAMA 2001;286(14):1748-53.

[9] Alvarado A. A practical score for the early diagnosis of acute appendicitis. Ann Emerg Med 1986;15(5):55764. doi: 10.1016/S0196-0644(86)80993-3.

[10] Howell JM, Eddy OL, Lukens TW, et al. Clinical policy: critical issues in the evaluation and management of emergency department patients with suspected appendicitis. Ann Emerg Med 2010;55(1):71-116. doi: 10.1016/j.annemergmed.2009.10.004.

[11] Chong CF, Adi MIW, Thien A, et al. Development of the RIPASA score: a new appendicitis scoring system for the diagnosis of acute appendicitis. Singapore Med J 2010;51(3):220-5.

[12] Terasawa T, Blackmore CC, Bent S, et al. Systematic review: computed tomography and ultra-sonography to detect acute appendicitis in adults and adolescents. Ann Intern Med 2004;141(7):537-46.

[13] Williams GR. Presidential address: a history of appendicitis. With anecdotes illustrating its importance. Ann Surg 1983;197(5):495-506.
[14] Subramani B, Kalaichelvan L, Selvam G, et al. Comparison between RIPASA and Alvarado scoring in diagnosing acute appendicitis. J Evid Based Med Healthc 2017;4(11):624-7.

[15] Ozao-Choy J, Kim U, Vieux U, et al. Incidental findings on computed tomography scans for acute appendicitis: prevalance, costs and outcome. Am Surg 2011;77(11):1502-9.

[16] Petrosyan M, Estrada J, Chan S, et al. CT scan in patients with suspected appendicitis: Clinical implications for the acute care surgeon. Eur Surg Res 2008;40(2):211-9.

[17] Douglas CD, Macpherson NE, Davidson PM, et al. Randomized controlled trial of ultrasonography in diagnosis of acute appendicitis, incorporating the Alvarado score. BMJ 2000;321(7266):919-22.

[18] Regar MK, Choudhary GS, Nogia C, et al. Comparison of Alvarado and RIPASA scoring systems in diagnosis of acute appendicitis and correlation with intraoperative and histopathological findings. Int Surg J 2017;4:175561.

[19] Jawaid A, Asad A, Motiei A, et al. Clinical scoring system: a valuable tool for decision making in cases of acute appendicitis. J Pak Med Assoc 1999;49(10):2549.

[20] Baidya N, Rodrigues G, Rao A, et al. Evaluation of Alvarado score in acute appendicitis: a prospective study. The Internet J Surg 2007;9:1528-42.

[21] Chan MY, Teo BS, Ng BL. The Alvarado score and acute appendicitis. Ann Acad Med Singapore 2001;30(5):510-2.

[22] Khan I, Ur Rehman A. Application of Alvarado scoring system in diagnosis of acute appendicitis. J Ayub Med Coll Abbottabad 2005;17(3):41-4.

[23] Al-Hashemy AM, Seleem MI. Appraisal of the modified Alvarado score for acute appendicitis in adults. Saudi Med J 2004;25(9):1229-31.

[24] Jang SO, Kim BS, Moon DJ. Application of Alvarado score in patients with suspected appendicitis. Korean J Gastroentrol 2008;52(1):27-31. 